dent of its manufacture which deprives iron of all its useful properties is not owing to a combination of iron and nitrogen. This is a point not to be neglected in my future researches.

Such are the new facts relative to the history of nitride of iron which I wish to make known to the Academy. I will sum them up in a few words:-

1. The object of my first experiments was to reproduce and prove the exactness of the experiments M. Despretz has described in hig paper on nitride of iron.

2. I then established the fact that the body produced by the reaction of ammoniacal gas on red-hot iron is really nitride of iron, and not of amidide; it contains no hydrogen.

3. It results from my experiments that the direct combination of nitrogen and iron takes place chicfly when the metal is in a nascent state.

4. I have proved that nitride of iron is formed with the greatest facility by decomposing anhydrous protochloride of iron by ammoniacal gas. This method applies to the preparation of other metallic nitrides.

5. The composition of nitride of iron prepared by the action of ammoniacal gas either on iron or on protochloride of iron, is the same; it contains about 9.5 per cent. of nitrogen, and may be represented by the formula $\mathrm{Fe}_{5} \mathrm{~N}$.

6. Nitride of iron is completely modified when heated in a charcoal fire; is no longer decomposed by hydrogen; and appears to resemble steel.

In another Memoir I shall ascertain whether nitride of iron can be employed in the preparation of steel.-Comptes Rendus.

For the Journal of the Franklin Institute.

Strength of Materials: Deduced from the latest experiments of Barlow, Buchanan, Fairbairn, Hodgkinson, Stephenson, Major Wade, U. S. Ordnance Corps, and others. By Chas. H. Haswell, Civil and Marine Engineer.

No. 9.

(Continued from vol. xli, page 408.)

Torsional and Detrusive Strength.

Torsional Strength.

The torsional strength of any square bar or beam is as the cube of it side, and of any cylinder as the cube of its diameter. Hollow cylinders or shafts have greater torsional strength than solid ones containing the same volume of material.

The torsional angle of a bar, \&c., under equal pressures will vary as the length of the bar, \&c. Hence, the torsional strength of bars of like diameters are inversely as their lengths.

The strength of a cylindrieal prism compared to a square is as 1 to 85 .

When a bar, beam, \&c., having a length greater than its diameter, Vot. XLII.TThiRd SERTrs.-No. 1.-JeLY, 1861. 
is subjected to a torsional strain, the direction of the greatest strain is in the line of the diagonal of a square, and if a square be drawn on the surface of the bar, \&c., in its primitive form, it will become a rhombus by the action of the strain.

Tables of the Torsional Strength of Materials.

Deduced from the Experiments of Major Wade, U.S. A., and Reduced to an Uniform Measure of

One Inch Square or in Diameter, Weight or Stress applied at one foot in Length from Centre of Axis of the Muterial, and at the Face of the Axis or Journal.

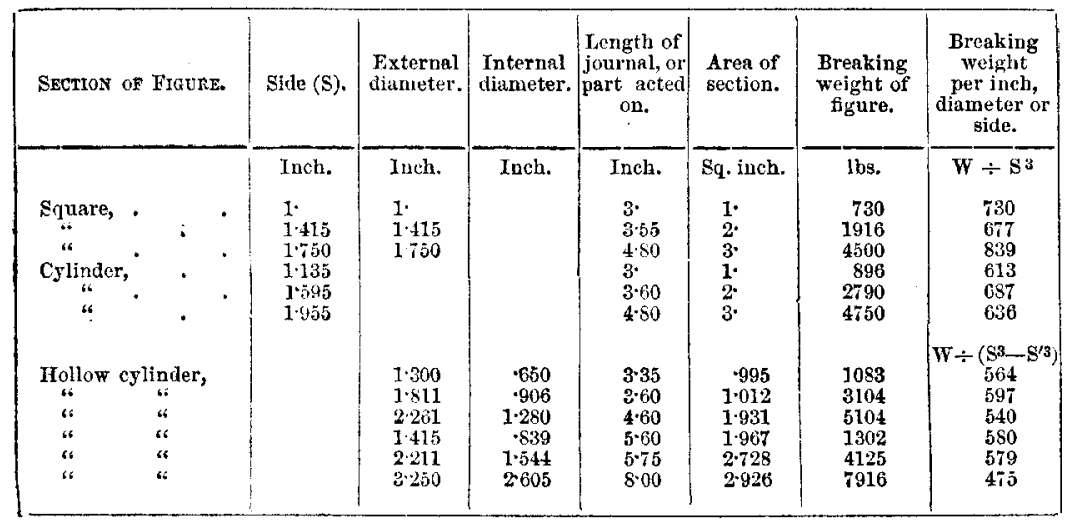

Summary of Preceding Results.

\begin{tabular}{|c|c|c|c|c|c|c|}
\hline \multirow{2}{*}{$\begin{array}{l}\text { Area of cross } \\
\text { section. }\end{array}$} & \multicolumn{6}{|c|}{ Breaking weight of figures. } \\
\hline & Square $t d^{2}$ & Cylinder $d^{3}$. & Area of section. & $\begin{array}{l}\text { Hollow cylin- } \\
\text { der } d^{3}-d^{\prime 3} \text {. }\end{array}$ & Area of section. & $\begin{array}{l}\text { Hollow cylin- } \\
\text { der } d^{3}-d^{\prime 3}\end{array}$ \\
\hline Inch. & Ibs. & lbs. & Inch. & lbs. & Ineh. & dbs. \\
\hline $\begin{array}{l}1 \\
\mathbf{2} \\
3\end{array}$ & $\begin{array}{l}730 \\
677 \\
840\end{array}$ & $\begin{array}{l}613 \\
698 \\
636\end{array}$ & $\begin{array}{r}.995 \\
1.931 \\
2.728\end{array}$ & $\begin{array}{r}563 \\
597 \\
540\end{array}$ & $\begin{array}{l}1.012 \\
1.967 \\
2.966\end{array}$ & $\begin{array}{l}585 \\
579 \\
476\end{array}$ \\
\hline Mean, & 749 & 649 & & 567 & & 547 \\
\hline
\end{tabular}

All of the bars were from the same mixture of common foundry iron, of a mean torsional strength of $644 \mathrm{lbs}$. per square inch of section.

From these results it appears that solid square shafts have about one-fifth less strength than solid cylinders of equal areas.

The stress which will give a bar a permanent set of $\frac{1}{2}^{\circ}$, is about ${ }_{10}^{7}$ ths of that which will break it, and this proportion is quite uniform, even when the strength of the material may vary essentially.

The strongest bars give the longest fractures.

Wrought iron, compared with cast iron, has equal strength under a stress which does not produce a permanent set, but this set commences under a less force in wrought iron than cast, and progresses more rapidly thereafter. The strongest bar of wrought iron acquired a permanent set under a less strain than a cast iron bar of the lowest grade. The mean values of cast and wrought iron and bronze, for bars of small diameters for a permanent set of $\frac{1}{2}^{\circ}$, are as $1 \cdot, \cdot 6$, and $\cdot 33$. 
TABLE of the Torsional Strength of Cast and Wrought Iron and Bronze, with their Values for different Diameters.

Length of Journal, or of the Bar or Beam submitted to struin, for which the Values are given, three times the Diameter or Side of the Shaft.

\begin{tabular}{|c|c|c|c|c|c|c|c|}
\hline \multirow{2}{*}{ FIGOTEE. } & \multirow{2}{*}{$\begin{array}{l}\text { Sperific } \\
\text { gravity. }\end{array}$} & \multirow{2}{*}{$\begin{array}{l}\text { Length of } \\
\text { journal or } \\
\text { side. }\end{array}$} & \multirow{2}{*}{$\begin{array}{l}\text { Brealsing } \\
\text { weight. }\end{array}$} & \multicolumn{4}{|c|}{ Value for diameter of } \\
\hline & & & & 2 ins. & 5 ins. & 10 ins. & 15 ins. \\
\hline CrLINDER. Cast IRON. & & Inch. & Iks. & & & & \\
\hline $\begin{array}{l}\text { Got commen eastings, } \\
\text { colitblast, }\end{array}$ & $7 \cdot 150$ & 8* & 583 & 170 & 115 & 305 & 100 \\
\hline $\begin{array}{l}\text { mean of } 8 \text { trials, } \\
\text { Gun iron, small bars. }\end{array}$ & $7 \cdot 3 \cdot 3$ & 8. & 705 & 175 & 120 & 110 & 105 \\
\hline greatest extreme, & 7.24 & 8 & 833 & 200 & 135 & 125 & 120 \\
\hline Crusper. Whovght Iros. & & & & & & & \\
\hline $\begin{array}{c}\text { perinanent set, } \\
\text { Bends without breaking, }\end{array}$ & $7 \cdot 855$ & 87. & $\left.\begin{array}{l}300 \\
622\end{array}\right\}$ & 130 & 128 & 125 & 123 \\
\hline CrLinjer. Bronze. & & & & & & & \\
\hline $\begin{array}{l}\text { Begins to yield, } \\
\text { permanent set, } \\
\text { Bends ithout breaking, }\end{array}$ & $\stackrel{8.710}{-}$ & 8. & $\begin{array}{l}\left.\begin{array}{l}102 \\
458\end{array}\right\} \\
4\end{array}$ & 55 & 45 & 35 & 33 \\
\hline Square Crst Iros, & $7 \cdot 200$ & $\begin{array}{l}3 \cdot \\
4 \cdot 8\end{array}$ & $\left.\begin{array}{l}730 \\
840\end{array}\right\}$ & 220 & 150 & 140 & $13 \pm$ \\
\hline$\therefore$ WrOEght ImOS, & $7 \cdot 855$ & 3 & - & 170 & 165 & 160 & 162 \\
\hline FoLLOW CXLINDER. " " & & & & & & & \\
\hline 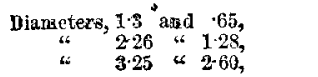 & $\overline{-}$ & $\begin{array}{l}3 \cdot 35 \\
4 \cdot 60 \\
8\end{array}$ & $\begin{array}{l}1083 \\
5104 \\
7916\end{array}$ & $\begin{array}{l}163 \\
153 \\
135\end{array}$ & $\begin{array}{r}110 \\
105 \\
90\end{array}$ & $\begin{array}{r}100 \\
96 \\
83\end{array}$ & $\begin{array}{l}96 \\
92 \\
80\end{array}$ \\
\hline
\end{tabular}

The experiments above given were made with bars not exceeding 2 inches in diameter; the relations given, therefore, do not hold, as the diameters are increased, in consequence of the shrinking of the cast metals in cooling, which by cooling at the outer surface first, draws the metal from the centre and in effect gives to a bar or shaft the properties of a hollow cylinder. In shafts of 10 inches in diameter, the torsional strength of wrought iron is considered fully equal to that of cast iron, and with larger diameters it would be much greater but that it suffers deterioration as its diameter increases, from the inerensed difficulty in effecting welding and the reduction of the metal to a fibrous texture.

The following rules in all instances are purposed to apply to the diameters of the journals of shafts, or to the diameter or side of the bearings of the beams, \&e., where the length of the journal or the distance upon which the strain bears, does not greatly exceed the diameter of the journal or side of beam, \&c., hence, when the length or distanee is greatly increased, the diameter or side must be correspondingly inereased.

To ascertain the Torsional Strength of Square or Round Shafts, \&e.

Rute.-Multiply the value in the preceding tables by the cube of the side or of the diameter of the shaft, \&c., and divide the product by the distance from the axis at which the stress is applied in feet; the quotient will give the resistance in pounds. 
EXAMPLE.-What torsional stress may be borne by a cast iron shaft of the best material, 2 inches in diameter, the power being applied at 2 feet from its axis?

$$
125 \times 2^{3}=1000 \text { and } \frac{1000}{2}=500 \mathrm{lbs} .
$$

To ascertain the Diameter of a Square or Round Shaft, \&c., to resist Torsion.

RuLE.-Multiply the extreme of pressure on the crank pin, or at the pitch line of the pinion, or at the centre of effect on the blades of the wheel, \&c., that the shaft may at any time be subjected to, by the length of the crank or radius of the wheel in feet, \&c.; divide their product by the value in the preceding tables, and the cube root of the quotient will give the diameter of the shaft or its journal in inches.

EXAMPLE.-What should be the diameter for the journal of a wrought iron water-wheel shaft, the extreme pressure on the crank pin being $59,400 \mathrm{lbs}$. and the crank 5 feet in length?

$$
\begin{aligned}
& \frac{59400 \times 5}{125}=2376 \text { and } \\
& \sqrt[3]{2376}=13.34 \text { ins. }
\end{aligned}
$$

When two Shafts are used, as in Steam Vessels with one engine, \&c.

RuLE.-Divide three times the cube of the diameter for one shaft by four, and the cube root of the quotient will give the diameter of the shaft in inches.

EXAMPLE.- The area of the journal of a shaft is 113 inches, what should be the diameter, two shafts being used?

Diameter for area of $113=12$.

$$
\text { Then } \frac{3 \times 12^{3}}{4}=1296 \text { and } \sqrt[3]{ } 1296=10 \cdot 9 \text { ins. }
$$

NотE.-The examples here given are deduced from instances of successful practice; where the diameter has been less, fracture has almost universally taken place, the strain being increased beyond the ordinary limit.

2. When the work to be performed is of a regular character and the stress is consequently uniform, the proportion of $\frac{3}{4}$ ths may be reduced to $\frac{5}{8}$ ths.

$$
\text { Relative values of Cast and Wrought Iron. }
$$

When shafts of less diameter than 12 inches are required the values here given may be slightly reduced, according to the quality of the iron and the diameter of the shaft to be used; but when they exceed this diameter, the values may not be increased in a like manner, as the strength of a cast or a wrought iron shaft decreases as their diameters increase.

Grier makes the difference between cast and wrought iron shafts for all diameters as .963 to 1.000 .

To ascertain the Torsional Strength of Hollow Shafts and Cylinders.

RULE.-From the fourth power of the exterior diameter subtract the fourth power of the interior diameter and multiply the remainder by the value of the material; divide this product by the product of the ex- 
terior diameter and the length or distance from the axis at which the stress is applied in feet: the quotient will give the resistance in pounds.

Example. - What torsional stress may be borne by a cast iron hollow shaft, having diameters of 3 and 2 inches, the power being applied at 1 foot from its axis?

$$
\begin{aligned}
& 3^{4}-2^{4} \times 105=81-16 \times 105=6825 \\
& \text { which } \quad \div 3 \times 1=\frac{6825}{3}=2275 \mathrm{lbs} .
\end{aligned}
$$

The order of journals of shafts, with reference to the degree of torsional strength to which they are subjected, is as follows:-

1. Fly-wheel shafts.

2. Water-wheel shafts.

3. Secondary shafts.

4. Tertiary shafts, \&c., \&c.

Hence, the diameters of their journals may be reduced in this order.

\begin{tabular}{|c|c|c|c|c|c|c|c|}
\hline Materials. & & Valote. & MA & RIALS. & & & Value. \\
\hline $\begin{array}{l}\text { Cast Iron, } \\
\text { Wrought Iron, } \\
\text { do } \\
\text { Cast Steel, } \\
\text { Shear do, } \\
\text { Blistered do, } \\
\text { Gun Metal (bronze), }\end{array}$ & \begin{tabular}{r|r}
$1 \cdot 00$ \\
$1 \cdot 12$ \\
$1-05$ \\
$2 \cdot 17$ \\
$1 \cdot 88$ \\
$1 \cdot 84$ \\
$\cdot 33$
\end{tabular} & $\begin{array}{r}112 \\
125 \\
117 \\
243 \\
210 \\
206 \\
37\end{array}$ & $\begin{array}{l}\text { Brass, } \\
\text { Copper, . } \\
\text { rin, } \\
\text { Lead, } \\
\text { Oak, } \\
\text { White Pine, }\end{array}$ & $\begin{array}{l}\cdot \\
\cdot \\
\cdot\end{array}$ & $\begin{array}{l}: \\
\cdot \\
\cdot\end{array}$ & $\begin{array}{r}\cdot 28 \\
\cdot 25 \\
\cdot 15 \\
\cdot 11 \\
2 \cdot 24 \\
2 \cdot 05\end{array}$ & $\begin{array}{r}31 \\
28 \\
17 \\
12 \\
250 \\
228\end{array}$ \\
\hline
\end{tabular}

Relative Value of Different Materials to Resist Torsion. By English Authors.

Relative Value of Different Figures to Resist Torsion,

\begin{tabular}{|c|c|c|c|c|c|c|}
\hline \multirow{2}{*}{$\begin{array}{l}\text { Solid } \\
\text { Cylinder. }\end{array}$} & \multirow{2}{*}{$\begin{array}{l}\text { Solid } \\
\text { Square. }\end{array}$} & \multicolumn{5}{|c|}{$\begin{array}{l}\text { Hollow Cylinders, the interior and exterior diameters of which are } \\
\text { in the proportion of }\end{array}$} \\
\hline & & 4 to 10 . & 5 to 10. & 6 to 10 & 7 to 10 & 8 to 10. \\
\hline $1 \cdot 600$ & .8750 & $1 \cdot 2656$ & $1 \cdot 4433$ & 1.7000 & 20864 & 2.7377 \\
\hline
\end{tabular}
Having Equal Sectional Areas.

\section{Detrusive Strength.}

The Detrusive strength of any body is directly as its depth or thickness.

Table of the Results of Experiments upon the Detrusive Strength of Metals.

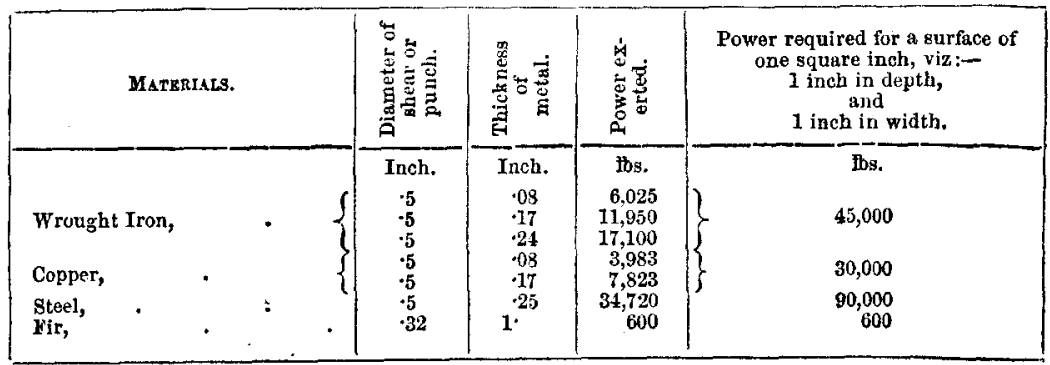

Note-The free use of oil reduces the power required very materially. 
Comparison between Detrusive and Transverse Strengths.

Assuming the compression and abrasion of the metal in the application of a punch of one inch in diameter to extend to one-eighth of an inch beyond the diameter of the punch, the comparative resistance of wrought iron to detrusive and transverse strain, the latter estimated at $600 \mathrm{ths}$. per square inch, for a bar one foot in length, is as $2 \cdot 5$ to 1.

Character of Strains to which Connecting Rods, Straps, Gibs, and Keys are subjected.

Heads of Rods.-At sides of keyholes, tensile and compressive; at back of keyholes, detrusive.

Straps.-At crown and sides of keyhole, tensile; at back of keyholes, detrusive.

Gib.-Transverse, uniformly loaded along its length, fixed at both ends.

Key.-With single gib, transverse, uniformly loaded along its length, supported at both ends.

Key.-With double gib, transverse, uniformly loaded along its length, fixed at both ends.

Woods.

When a Beam or any piece of wood is let in (not mortised) at an inclination to another piece, so that the thrust will bear in the direction of the fibres of the beam that is cut, the depth of the cut at right angles to the fibres, should not be more than one-fifth of the length of the piece, the fibres of which, by their cohesion, resist the thrust.

To ascertain the Force necessary to Punch Iron or Copper Plates.

RULE.-Multiply the product of the diameter of the punch and the thickness of the metal by 150,000 if for wrought iron, and by 96,000 if for copper, and the product will give the power required, in pounds.

(To be Continued.)

For the Journal of the Franklin.Inatitute.

Strength of Cast Iron and Wrought Iron Pillars: A series of Tables deduced from several of Mr. Eaton Hodgkinson's Formulæ, showing the Breaking Weight and Safe Weight of Cast Iron and Wrought Iron Uniform Cylindrical Pillars. By Wm. Bryson, Civ. Eng.

(Continued from page 396, vol. sli.)

Tables showing the calculated breaking weight and safe weight of uniform solid cylindrical pillars of cast iron, and the calculated weight of metal contained in each pillar.

Formula for the breaking weight of solid pillars of cast iron, their length or height exceeding 25 times their diameters, both ends of the pillars being flat and firmly fixed:-

$$
\mathrm{W}=44 \cdot 16 \frac{\mathrm{D}^{3.55}}{\mathrm{~L}^{1.7}} .
$$

